\title{
Thallium stable isotope fractionation in a model plant
}

\author{
A. VANEK ${ }^{1 *}$, O. HOLUBIK ${ }^{1}$, M. MiHALJEVIC ${ }^{2}$, V.

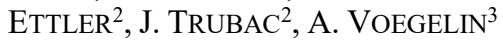 \\ ${ }^{1}$ Department of Soil Science and Soil Protection, Czech \\ University of Life Sciences Prague, Czech Rep. \\ (*correspondence: vaneka@af.czu.cz) \\ ${ }^{2}$ Institute of Geochemistry, Mineralogy and Mineral \\ Resources, Charles University, Czech Republic \\ ${ }^{3}$ Eawag, Swiss Federal Institute of Aquatic Science and \\ Technology, Switzerland
}

Here, we studied thallium (Tl) isotope fractionation in white mustard grown hydroponically at different $\mathrm{Tl}$ doses. Thallium isotope signatures in plants indicated preferential incorporation of the light ${ }^{203} \mathrm{Tl}$ isotope during $\mathrm{Tl}$ uptake from the solution. Negative isotope fractionation was even more pronounced in dependence on how much the available Tl pool decreased. This finding corresponds to the concept of isotope overprinting related to a high contamination level in the growing media (solution or soil). Regarding Tl translocation in plants, we observed a large $\mathrm{Tl}$ isotope shift with an enrichment in the heavy ${ }^{205} \mathrm{Tl}$ isotope in the shoots relative to the roots in treatments with low/moderate solution $\mathrm{Tl}$ concentrations $(0.01 / 0.05 \mathrm{mg} \mathrm{Tl} / \mathrm{L})$, with the corresponding $\alpha^{205 / 203} \mathrm{Tl}$ fractionation factors of $\sim 1.007$ and 1.003, respectively. This finding is probably a consequence of specific (plant) reactions of $\mathrm{Tl}$ replacing $\mathrm{K}$ in its cycle. The role of the S-coordinated $\mathrm{Tl}(\mathrm{I})$ complexes in the total process of $\mathrm{Tl}$ accumulation and $\mathrm{Tl}$ isotope fractionation in plants, however, still remains unclear, since we do not have indication for that on the basis of X-ray absorption spectroscopy, suggesting that $\mathrm{Tl}$ was mainly present as free/hydrated $\mathrm{Tl}^{+}$ion or chemically bound to O-containing functional groups of (soluble) organic compounds.

In summary, our findings indicate that the tracing of $\mathrm{Tl}$ isotopes could be a tool how to better understand $\mathrm{Tl}$ transfers between the substrate and plant, but similarly to other trace metals, Tl speciation seems to play an important role in the strategies of $\mathrm{Tl}$ plant uptake/avoidance. However, these $\mathrm{Tl}$ processes should be verified by further experiments also with other plant species, more complex substrates and/or using more sophisticated approach depicting effects of individual physiological processes on $\mathrm{Tl}$ isotope shifts among individual plant parts. 